Democracy, Political Equality, and Majority Rule

Author(s): by Ben Saunders

Reviewed work(s):

Source: Ethics, Vol. 121, No. 1 (October 2010), pp. 148-177

Published by: The University of Chicago Press

Stable URL: http://www.jstor.org/stable/10.1086/656474

Accessed: 07 /06/2012 09:04

Your use of the JSTOR archive indicates your acceptance of the Terms \& Conditions of Use, available at http://www.jstor.org/page/info/about/policies/terms.jsp

JSTOR is a not-for-profit service that helps scholars, researchers, and students discover, use, and build upon a wide range of content in a trusted digital archive. We use information technology and tools to increase productivity and facilitate new forms of scholarship. For more information about JSTOR, please contact support@jstor.org. 


\section{Democracy, Political Equality, and Majority Rule*}

\section{Ben Saunders}

Democracy is commonly associated with political equality and/or majority rule. This essay shows that these three ideas are conceptually separate, so the transition from any one to another stands in need of further substantive argument, which is not always adequately given. It does this by offering an alternative decision-making mechanism, called lottery voting, in which all individuals cast votes for their preferred options but, instead of these being counted, one is randomly selected and that vote determines the outcome. This procedure is democratic and egalitarian, since all have an equal chance to influence outcomes, but obviously not majoritarian.

Democracy is commonly associated with political equality and/or majority rule. This essay shows that these three ideas are conceptually separate, so the transition from any one to another stands in need of further substantive argument, which is not always adequately given. It does this by offering an alternative decision-making mechanism, called lottery voting, in which all individuals cast votes for their preferred options but, instead of these being counted, one is randomly

* This article is based on my DPhil thesis, "Democracy-as-Fairness: Justice, Equal Chances and Lotteries" (University of Oxford, 2008). While writing it I incurred many debts, most notably to my supervisor, David Miller, and the Arts and Humanities Research Council, who funded the majority of my studies. Work in progress was presented at various venues (Oxford, Warwick, and Manchester), and something like this article to the Oxford Moral Philosophy seminar (June 2008), Cerberus, the Balliol College Oxford PPE Society (November 2008), the Corpus Christi College Oxford Philosophy Society (March 2009), and to audiences at the University of Manchester (July 2009) and University of York (August 2009). I would like to thank those audiences and, in particular, Gustaf Arrhenius, Adrian Blau, Conall Boyle, Daniel Butt, Krister Bykvist, Matthew Clayton, G. A. Cohen, Oliver Dowlen, Sarah Fine, Alan Hamlin, Robert Jubb, Fabienne Peter, Jonathan Quong, Andrew Reeve, Keith Sutherland, Stuart White, Karl Widerquist, and Jens Ziska. Special thanks go to my examiners, David Estlund and Adam Swift, and to two anonymous reviewers and the editors of the journal for their comments.

Ethics 121 (October 2010): 148-177

(C) 2010 by The University of Chicago. All rights reserved. 0014-1704/2010/12101-0005\$10.00 
selected and that vote determines the outcome. This procedure is democratic and egalitarian, since all have an equal chance to influence outcomes, but obviously not majoritarian.

It is often thought that there is a straightforward entailment from democracy, to political equality, to majority rule. It is commonly assumed that if the people should rule then they must do so on an equal basis (since inequality smacks of oligarchy) and that, if all count equally, more votes must count for more. ${ }^{1}$ However, democracy, political equality, and majority rule are three distinct concepts and no one of these logically entails either of the others. ${ }^{2}$ It remains possible that substantive normative argument can establish that, for instance, the best or even only justifiable form of democracy is an egalitarian one. My purpose is not to settle all of these normative questions, which would be too great a task for a single essay. I attempt to show that the alternative to majority rule that I offer (lottery voting) has something to be said for it in at least some circumstances, but this is primarily to underline the real need for justifications of majority rule (as opposed to democracy or political equality).

It is necessary, before proceeding further, to stipulate how democracy, political equality, and majority rule are to be understood:

Democracy: The decisions made by a group must be appropriately responsive to the expressed wishes of the members of that group. ${ }^{3}$

Political equality: Each group member must have an equal (chance of) influence over the group's decisions.

Majority rule: The option that gets the most votes should be the group decision.

These definitions are intended to be as minimal and ecumenical be-

1. For example, Robert Dahl and Charles Lindblom, Politics, Economics and Welfare: Planning and Politico-Economic Systems Resolved into Basic Social Processes, 2nd ed. (Berkeley: University of California Press, 1976), 44, claim that if the minority prevail over the majority then their votes must be given greater weight. As I show below, this is not the case.

2. Of course, one can use the words any way one likes. One could define 'democracy' semantically, in terms of majority rule; but one would then presumably have to acknowledge both that democracy, so defined, need not be of any value and that some other, nondemocratic system could be preferable. In this case, the following argument should be taken as showing that there are conceivable nondemocratic systems that respect the ideals of citizen sovereignty and political equality and thus may be as desirable as democracy.

3. The essential idea here seems to be the extent of the franchise. Democracy is rule of the majority, as opposed to the few, but this does not entail that those decision makers must operate by majority rule. I explore this contrast, and the definition of democracy, in "A Relativized Definition of 'Democracy" (unpublished manuscript, University of Oxford). 
tween different theories of democracy as possible. Political equality, for example, is consistent with either a narrowly aggregative view (one person, one vote; one vote, one weight) or with deliberative democracy, provided that all have equal access to the deliberative forum.

Democracy, so defined, is a matter of citizen sovereignty or the responsiveness of decisions to the expressed wishes of the people. This, I believe, is the idea's essential content. ${ }^{4}$ Some propose to build political equality into their definition of democracy. ${ }^{5}$ This is unhelpful, however, since arguments may be given why some ought to have more votes than others, for instance, because they have more at stake in the matter being decided. ${ }^{6}$ Whether or not these proposals can be justified substantively, there seems no reason to exclude such a system from being democratic, provided that everyone gets some influence. Inequality will threaten democracy if it reaches the point where some effectively have no influence at all (for instance, if one person has a million votes), but small inequalities-such as between those in differently sized districts-may not matter at all. ${ }^{7}$ I shall say relatively little about political equality in what follows. The main thrust of my argument concerns the connection between democracy and majority rule, so I shall simply grant the desirability of political equality. My argument will be that democracy, even combined with political equality, does not require majority rule.

Since democracy, political equality, and majority rule are distinct ideas, each stands in need of separate justification. It is not, here, my intention to attack or defend any of them, though I aim to show that the last of these is rarely given adequate general justification. Majority

4. Similar characterizations are proposed by Charles Beitz, Political Equality: An Essay in Democratic Theory (Princeton, NJ: Princeton University Press, 1989), 17; and David Estlund, Democratic Authority: A Philosophical Framework (Princeton, NJ: Princeton University Press, 2008), 38. Note that this is proposed as a sortal classification, allowing us to describe regimes as democratic or not. It may be thought that democracy is a scalar concept, coming in degrees. I have some sympathy for this idea (particularly, for example, if it is connected to the extent of the franchise). I cannot give a full argument about the definition of democracy here, but I assume it will sometimes be useful or necessary to adopt a sortal classification and that this definition is then appropriate.

5. For example, Robert Dahl, Democracy and Its Critics (New Haven, CT: Yale University Press, 1989), 109-11, and On Democracy (New Haven, CT: Yale University Press, 1998), 3738.

6. As proposed by Harry Brighouse and Marc Fleurbaey, "Democracy and Proportionality," Journal of Political Philosophy 18 (2010): 137-55. For a related proposal, see David Heyd and Uzi Segal, "Democratically Elected Aristocracies," Social Choice Welfare 27 (2006): $103-27$.

7. Doubts about the necessity of political equality are expressed by Estlund, Democratic Authority, 206-22; and Andrew Rehfeld, The Concept of Constituency: Political Representation, Democratic Legitimacy, and Institutional Design (New York: Cambridge University Press, 2005), 193-97. 
rule may be unobjectionable in many contexts, but there are some cases-like when it permanently excludes a certain minority ${ }^{8}$ where it may be not only unjust but also undemocratic, because members of this minority are effectively excluded from influence altogether. Though a few others have before questioned the central place given to majority rule, less attention has been given to describing alternative institutions. ${ }^{9}$ I shall outline an alternative procedure, lottery voting, that satisfies the conditions of democracy and political equality. ${ }^{10}$

In lottery voting, each person casts a vote for their favored option but, rather than the option with most votes automatically winning, a single vote is randomly selected and that one determines the outcome. ${ }^{11}$ This procedure is democratic, since all members of the community have a chance to influence outcomes, but is not majority rule, since the vote of someone in the minority may be picked. It is, as I describe it, egalitarian, since all have an equal chance of being picked. ${ }^{12}$ It gives each voter an equal chance of being decisive, but voters do not have equal chances of getting their way-rather, the chance of each option winning is proportional to the number of votes it obtains. This shows that democracy and political equality do not

8. These minorities may be identified simply by their political preferences, though they may also share ascriptive characteristics such as ethnicity. Of course, we may want to exclude some minorities, e.g., the Ku Klux Klan, but this is because their preferred policies are unjust rather than because they are minorities. I address such concerns in Sec. V.

9. For instance, Peter Jones, "Political Equality and Majority Rule," in The Nature of Political Theory, ed. David Miller and Larry Siedentop (Oxford: Clarendon, 1983), 155-82; and Mathias Risse, "Arguing for Majority Rule," Journal of Political Philosophy 12 (2004): $41-64$.

10. This name comes from Akhil Reed Amar, "Choosing Representatives by Lottery Voting," Yale Law Journal 93 (1984): 1283-1308, although he proposes it only for electing representatives, whereas I suggest that groups could use it for decision making. Similar proposals, under various names, are found in Bruce Ackerman, Social Justice in the Liberal State (New Haven, CT: Yale University Press, 1980), 285-89; David Estlund, "Beyond Fairness and Deliberation: The Epistemic Dimension of Democratic Authority," in Deliberative Democracy: Essays on Reason and Politics, ed. James Bohman and William Rehg (Cambridge, MA: MIT Press, 1997), 173-204, 191-94; Jones, "Political Equality and Majority Rule," 17071; and Robert Wolff, In Defence of Anarchism (New York: Harper \& Row, 1970), 44-45, but none of these explore the possibility at length.

11. I am assuming a group making decisions directly. Though the decision could in principle be the appointment of a representative here there are other concerns in play (we care not only that a particular representative be the choice of a particular constituency but also about the overall composition of the group of representatives). We may favor different voting systems for different purposes and nothing I say contradicts this; my point is merely that lottery voting is a possibility, not that it is the best procedure for any particular form of decision making.

12. It is also compatible with weighted voting. Since each vote has an equal chance of selection, one person can be given more influence simply by giving them more votes. 
conceptually require majority rule. Moreover, I will argue that there are no clearly decisive general reasons to prefer majority rule to lottery voting in all cases. The possibility of lottery voting therefore demonstrates the need to distinguish more carefully between arguments for democracy, for political equality, and for majority rule, since the former (even in conjunction) do not entail the latter. If we can be democrats without being majoritarians then arguments for majority rule are necessary. In practice, the choice between majority rule and lottery voting will likely depend on contextual factors, such as whether there is a permanent minority in the society in question.

Section I begins by identifying three ways of justifying democracy; as an intrinsically just procedure, as conducive to substantively just or good outcomes, and for its valuable by-products. Section II argues that considerations of intrinsic fairness do not necessarily justify majority rule, since fairness can be satisfied by nondemocratic procedures like lotteries, and majority rule may not be fair in certain conditions, such as where there is a permanently excluded minority. Section III argues that instrumental considerations do not necessarily favor majority rule either, since it will be a contingent matter whether majority rule or lottery voting better conduces to the good consequences in question, whether better decisions or valuable by-products of the procedure. It seems that no general argument for democracy implies a commitment to majority rule. Section IV presents six arguments that have been offered specifically for majority rule and argues that none decisively favor majority rule over lottery voting. Finally, Section V considers and rejects four obvious objections to lottery voting, and Section VI concludes.

\section{WHY DEMOCRACY?}

Historically, arguments for democracy have not always distinguished it from majority rule. Consequently, we find democracy justified on grounds like satisfying most people's preferences is likely to be better from a utilitarian point of view or mean that the regime enjoys greater perceived legitimacy. ${ }^{13}$ We should not, however, beg the question against nonmajoritarian forms of democracy. At its most abstract, democracy simply means rule by the people. This, I take it, implies a procedure that is responsive to people's expressed preferences and that is broadly inclusive (since the contrast with oligarchy lies in the extent of the franchise), but it need not be egalitarian or, as I shall show below, majoritarian. While the best or most defensible form of democracy may indeed be based on political equality or majority rule,

13. Alf Ross, Why Democracy? (Cambridge, MA: Harvard University Press, 1952), 42- 
that is a further, substantive question. We should look first for the most general arguments for democracy.

Arguments for democracy can be subdivided into intrinsic and instrumental defenses. The former defend democracy either as its own sui generis value, which is unlikely to convince anyone who is not already a democrat, or as a requirement of some other shared value. Republicans, for instance, may see democracy as an essential ingredient of freedom as nondomination. ${ }^{14}$ Others regard democracy as a requirement of justice, because giving everyone a vote is part of respecting them as an equal. ${ }^{15}$ I focus on the justice-based argument for democracy, though I believe my case could be extended to other values. It should be noted that, though these arguments usually assume political equality, this is not necessary. While the generic principle of justice requires that like cases be treated alike, it may also require us to treat relevantly unlike cases differently and thus require a form of geometric proportionality ${ }^{16}$ If we find some basis on which to defend an equal right to equal participation, then justice will indeed require not only democracy, in its most abstract sense, but also political equality, thereby restricting the permissible range of democratic systems. However, if we accept that people have unequal claims to rule or participation, then we may have an argument, based on justice, for inegalitarian democracy. ${ }^{17}$ For instance, if some decision has greater effects on women than men, and we accept that people's say ought to be proportionate to what they have at stake in the decision, then the just democratic solution may give both men and women some influence, but women a greater share proportional to their greater stakes.

The second way of arguing for democracy is instrumentally. Such defenses claim that there is nothing valuable about democratic procedures in themselves; they are justified only when and because they

14. For example, Philip Pettit, "Republican Freedom and Contestatory Democracy," in Democracy's Value, ed. Ian Shapiro and Casiano Hacker-Cordòn (Cambridge: Cambridge University Press, 1999). I explore this line in "Republicanism and Abstention" (unpublished manuscript, University of Oxford) and shall say little further about republicanism here.

15. This line is taken by Thomas Christiano, The Constitution of Equality (Oxford: Oxford University Press, 2008).

16. For a classic argument, see Aristotle, Nicomachean Ethics (Indianapolis: Hackett, 1999), bk. 5. For a modern argument that fairness requires proportionate satisfaction of competing claims, see John Broome, "Fairness," Proceedings of the Aristotelian Society 91 (1990-91): 87-101. For discussion of Broome's views, see Brad Hooker, "Fairness," Ethical Theory and Moral Practice 8 (2005): 329-52; and Ben Saunders, "Fairness between Competing Claims," Res Publica 16 (2010): 41-55.

17. Of the sort proposed in Brighouse and Fleurbaey, "Democracy and Proportionality." 
produce good consequences. We can distinguish two forms of instrumental argument. First, outcome-based arguments focus on the decisions that are made. ${ }^{18}$ These could, in principle, have been reached by nondemocratic means, such as by a group of enlightened guardians, but-one who defends democracy on these grounds must maintainit is more likely that they will be arrived at by a popular vote. Again, those who endorse this argument are not committed to political equality. ${ }^{19}$ In fact, they would presumably accept whatever political arrangements are most likely to lead to the best decisions. If it turned out that plural voting produced better decisions, the only question is whether they would call this 'democracy' or abandon that term altogether.

Outcome-based arguments are, obviously, contingent defenses of democracy, since it is an empirical question how the favored outcomes are best realized. A second form of instrumental argument, however, focuses on by-products of the democratic process, which may not be realized by other means. For example, J. S. Mill favors (a nonegalitarian form of) democracy on the grounds that considering questions of the common good leads to a more active and virtuous citizenry, ${ }^{20}$ while Richard Vernon focuses on the tendency of democratic procedures to stimulate public reason and debate..$^{21}$ These arguments share something in common with the intrinsic defenses of democracy, since the procedure is essential to realizing the benefits that they focus on. There is a difference, however, between valuing the procedure intrinsically, as part of what it is to treat people justly, and valuing it instrumentally, even if it is a necessary means to the ends sought. Moreover, as the example of Mill shows, those who defend democratic procedures on the grounds of their by-products are not thereby committed

18. The clearest defender of such an approach is Richard Arneson, "Defending the Purely Instrumental Account of Democratic Legitimacy," Journal of Political Philosophy 11 (2003): 122-32, and "Democracy Is Not Intrinsically Just," in Justice and Democracy: Essays for Brian Barry, ed. Keith Dowding, Robert E. Goodin, and Carole Pateman (Cambridge: Cambridge University Press, 2004), 40-58. Estlund's epistemic proceduralism also seems to belong to this category, although he adds a qualified acceptability requirement; see Estlund, Democratic Authority, 40-44. This category also includes "minimalist" defenses of democracy, for instance, Joseph Schumpeter, Capitalism, Socialism and Democracy (London: G. Allen \& Unwin, 1943), chap. 22; and Adam Przeworski, "Minimalist Conception of Democracy: A Defense," in Shapiro and Hacker-Cordòn, Democracy's Value, 23-50.

19. For example, Beitz, Political Equality, 31-46; and Brighouse and Fleurbaey, "Democracy and Proportionality," 142.

20. John Stuart Mill, "Considerations on Representative Government," in On Liberty and Other Essays, ed. John Gray (Oxford: Oxford University Press, 1998), chap. 3.

21. Richard Vernon, Political Morality: A Theory of Liberal Democracy (London: Continuum, 2001) 
to political equality, since one may think that these by-products will be equally-or even better-produced by inegalitarian procedures.

A full defense of democracy is beyond the scope of this essay, and I cannot, here, adjudicate among these different arguments. My point is that none of them necessarily require either political equality or -as I will argue in the following two sections-majority rule. It may be, as I will consider in Section IV, that one's particular reason for favoring democracy also gives one reason to favor majority rule. For example, one may think that democracy is likely to produce better outcomes because one believes that democracies satisfy the conditions of Condorcet's jury theorem, which tells us that (under said assumptions) the majority are more likely to be right about a matter of fact than any single individual. ${ }^{22}$ One can, however, hold any of the three general positions outlined in this section without necessarily being committed to majority rule-such a commitment always stands in need of further argument to show that majority rule is indeed just or the best way to produce the desired outcomes.

\section{INTRINSIC FAIRNESS AND MAJORITY RULE}

First, there are those who advocate democracy as an intrinsically just procedure or way of treating everyone fairly. ${ }^{23}$ It is unclear, though, whether majority rule always does treat all persons equally. Simply giving everyone an equal vote is not enough if some votes are worth more than others. One reason this might be so is if district sizes were greatly unequal. Another is if one person's vote was more likely to be pivotal than another's, simply because of how others vote. This is easily seen if a bloc of voters always votes together, effectively becoming one person with a more-weighty vote. If we have nine people, each with one vote, and five always vote together, then they will always be a majority, so majority rule denies the other four any influence whatsoever. ${ }^{24}$ Members of permanent minorities often complain that ma-

22. For explanations of Condorcet's jury theorem, see Estlund, Democratic Authority, 223-30; and Przeworski, "Minimalist Conception," 26-30.

23. Here I use 'just' and 'fair' interchangeably. For some possible contrasts, see Saunders, "Fairness between Competing Claims," 42-43.

24. The other four may sometimes get their way, when their wants happen to coincide with those of the five, but they have no influence-their votes never matter to this outcome. In reality it is unlikely that the five will always vote together, but such cases are possible with weighted voting. In 1958 the European Economic Community had a system of weighted votes that gave Luxembourg no power whatsoever. See Dan Felsenthal and Moshé Machover, The Measurement of Voting Power: Theory and Practice, Problems and Paradoxes (Cheltenham: Edward Elgar, 1998), 14; and Alan Taylor, Mathematics and Politics: Strategy, Voting, Power and Proof (New York: Springer-Verlag, 1995), 71-75. 
jority rule simply serves to exclude them from influence. ${ }^{25}$ Even defenders of majority rule are sensitive to this worry. ${ }^{26}$

It is generally agreed that majority rule is most defensible where society is divided by numerous cross-cutting cleavages, so that both majorities and minorities are fluid and changing. ${ }^{27}$ This means that those who win or lose on one decision have no grounds to assume that they will be in the same position on the next occasion, since they may find themselves in either a majority or a minority on any given issue. This condition is not satisfied when there is a permanent minority, whose preferences differ from those of the majority. Members of such a group know, in advance of any given vote, that they will be outnumbered and therefore lose. Consequently, it is hard to see why they should accept that majority rule treats them fairly. Since the procedure appears rigged against them from the start, it seems more like someone proposing that they agree to toss a biased coin to settle their disagreement.

It is useful to contrast democratic procedures to a lottery. Critics of intrinsic fairness-based arguments for democracy have often suggested that, if the only justification of democratic procedures is simply that they are fair to all parties, then it would be equally justified to use a lottery to decide between courses of action. ${ }^{28}$ If this claim is correct, which I think it is, then it does not show that fairness plays no part in justifying democracy, but only that it alone is insufficient. ${ }^{29}$

A simple lottery over options treats all citizens equally, giving all an equal expectation of getting their most preferred option (though actual levels of [dis]satisfaction may still be unequal). Such a lottery is obviously not democratic, however, since by assigning an equal probability to each possible outcome it disregards citizens' inputs altogether. A justification of democracy has to appeal to something beyond mere procedural fairness to explain this responsiveness. This, presumably, will involve some reference to the likely consequences of

25. For example, Lani Guinier, "No Two Seats: The Elusive Quest for Political Equality," Virginia Law Review 77 (1991): 1413-1514.

26. Christiano, The Constitution of Equality, 288-99.

27. For example, Robert Dahl, A Preface to Democratic Theory (Chicago: University of Chicago Press, 1956), 124-51; Giovanni Sartori, The Theory of Democracy Revisited (Chatham, NJ: Chatham House, 1987), 134-37; and Anthony McGann, The Logic of Democracy: Reconciling Equality, Deliberation, and Minority Protection (Ann Arbor: University of Michigan Press, 2006), 89-111.

28. Beitz, Political Equality, 76; Estlund, Democratic Authority, 66 and 82-84; Robert Goodin, "Democracy, Justice and Impartiality," in Dowding, Goodin, and Pateman, Justice and Democracy, 97-111, 99; William Nelson, On Justifying Democracy (London: Routledge \& Kegan Paul, 1980), 19.

29. I argue this more fully in "Estlund's Flight from Fairness," Representation 46 (2010): $5-17$. 
democratic procedures, although whether the relevant consequences will be decision outcomes or by-products of the procedures is still an open question.

We do not ordinarily think that the purpose of democracy is to realize the equal satisfaction of all groups. This can be seen if we consider cases where there is persisting disagreement over a number of decisions. Suppose, for example, that society is divided into two groups: economizers and aesthetes. ${ }^{30}$ The economizers care only about material possessions and will sacrifice other values for the sake of efficiency. The aesthetes, conversely, value beauty and the environment and are willing to pay more to preserve these ideals. Assume that three-quarters of the society are economizers, while one-quarter are aesthetes, and that they face regular trade-offs between economic efficiency and aesthetic values, for instance, in controls over pollution and matters of urban management (street cleaning, tree planting, etc.). Predictably, a majority each time will favor the cheaper option, even at the cost of aesthetic values, but, if there are four such decisions, it hardly seems fair for them all to go the way of the economizers. Were we to toss a coin over each decision, however, or simply take it in turns to satisfy each group, then the aesthetes would expect to get their way on half of the decisions, which also seems unfair, since they are only a quarter of the population.

It seems that what fairness requires here is proportionality, rather than blindly enforcing equality regardless of differences. Ideally, this might be proportionality of outcomes but, where that cannot be satisfied, proportionality of chances may be the best approximation. ${ }^{31}$ Democracy is a matter of fair decision-making procedures, rather than whatever produces substantively fair outcomes. Matters are complicated by the fact that we have unequal numbers on each side of the dispute. Thankfully, how to adjudicate fairly between competing groups of unequal sizes has been much discussed by certain moral philosophers debating the justifiability of interpersonal aggregation.

Taurek suggests that, in cases where we can save either one person's life or five other people's lives, we treat all individuals equally by tossing a coin, giving each person a 50 percent chance of survival. ${ }^{32}$ This "equal chances" solution has, however, seemed unsatisfactory to 68.

30. This example is adapted from Jones, "Political Equality and Majority Rule," 167-

31. Broome, "Fairness," 95; and Frances Kamm, "Equal Treatment and Equal Chances," Philosophy and Public Affairs 14 (1985): 177-94.

32. John Taurek, "Should the Numbers Count?" Philosophy and Public Affairs 6 (1977): 293-316. 
many. ${ }^{33}$ Scanlon suggests that, while tossing a coin may be a reasonable procedure between groups of equal size, the extra people in a larger group could reasonably reject a decision-making procedure that gave their presence no weight whatsoever and therefore concludes that one should save the greater number. ${ }^{34}$ Others have suggested that another way of counting each person's claim to be rescued equally would be to hold a weighted lottery. ${ }^{35}$ Surprisingly, while several participants in this debate reference democratic procedures ${ }^{36}$ there has been little attention paid to it by democratic theorists. ${ }^{37}$ The two cases are, however, structurally similar: we can satisfy either of two distinct groups and it is agreed that it would be fair to toss a coin were the groups of equal size. ${ }^{38}$ The crucial issue is what fairness requires when these groups are unequal in size; the prominent possibilities being still to toss a coin (equal chances), to save the greater number (majority rule), or to hold a proportionally weighted lottery (proportional chances).

Those who have considered the democratic solution to conflicts between unequally sized groups usually favor some form of proportionality ${ }^{39}$ This reflects the fact that democracy is a matter of rule by

33. For early responses, see Derek Parfit, "Innumerate Ethics," Philosophy and Public Affairs 7 (1978): 285-301; and Gregory Kavka, "The Numbers Should Count," Philosophical Studies 36 (1979): 285-94.

34. T. M. Scanlon, What We Owe to Each Other (Cambridge, MA: Harvard University Press, 1998), 229-35. For criticisms, see Michael Otsuka, "Scanlon and the Claims of the Many versus the One," Analysis 60 (2000): 288-93; Joseph Raz, "Numbers, with and without Contractualism," Ratio 16 (2003): 346-67; and Ben Saunders, "A Defence of Weighted Lotteries in Life Saving Cases," Ethical Theory and Moral Practice 12 (2009): 279-90.

35. This possibility was (to the best of my knowledge) first suggested by Kavka, "The Numbers Should Count," 294, and is also considered by Kamm, "Equal Treatment." Arguments for such a proposal can be found in Jens Timmerman, "The Individualist Lottery: How People Count, but Not Their Numbers," Analysis 64 (2004): 106-12; and Saunders, "A Defence of Weighted Lotteries."

36. See Kamm, "Equal Treatment," 181 and 191; Taurek, "Numbers," 310-14; and David Wasserman and Alan Strudler, "Can a Nonconsequentialist Count Lives?" Philosophy and Public Affairs 31 (2003): 71-94, 81 n. 18, and 92 n. 33.

37. The only case I am aware of is Risse, "Arguing," 50 n. 22.

38. The fairness of lotteries is accounted for by George Sher, "What Makes a Lottery Fair?" Noûs 14 (1980): 203-16; Broome, "Fairness"; Peter Stone, "Why Lotteries Are Just," Journal of Political Philosophy 15 (2007): 276-95; and Ben Saunders, "The Equality of Lotteries," Philosophy 83 (2008): 359-72. The use of lotteries to break tied votes is suggested by Brian Barry, Political Argument (London: Routledge \& Kegan Paul, 1965), 88; Robert Dahl, Democracy and Its Critics (New Haven, CT: Yale University Press, 1989), 141; Gerry Mackie, Democracy Defended (Cambridge: Cambridge University Press, 2003), 5, 50, and 84; and McGann, Logic, 62. It is also employed in practice; see Barbara Goodwin, Justice by Lottery, 2nd ed. (Exeter: Imprint Academic, 2005), 55, 198, and 255. 61.

39. Jones, "Political Equality and Majority Rule," 174-75; and Risse, "Arguing," 60- 
the people, not merely for the people. That is, it is not about equal satisfaction of preferences (as shown by the economizers and aesthetes example and our rejection of coin tossing), but equal respect for each person's agency. ${ }^{40}$ Each person's vote must have equal influence over what is done. ${ }^{41}$ Lottery voting reflects this by giving each voter an equal chance of being decisive. It does not follow that voters will be equally satisfied, or even that they should expect to be so, for this would be undemocratic where the split of opinion is unequal. Where our aim is to respect each person's input into decision making equally, however, a weighted lottery is one possibility. In fact, this solution seems more reasonable in most democratic cases than in the life saving case, because it seems more reasonable to share Taurek's assumption that neither alternative is impersonally worse (or, at least, that the option favored by the majority is necessarily likely to be better, given problems such as unequal preference intensities) ${ }^{42}$ and to assume that people want to be counted in the decision making, rather than simply to get their way.

Goodin argues that, where we toss a coin to break a tie, whichever side wins the lottery may be legitimate, but is no more democratic, for that status depends on winning people's votes. ${ }^{43}$ So it is, I would argue, with lottery voting. Since democracy is supposed to be rule by all of the people, the ideal would be unanimity. Given a difference of opinion or conflict of interest, some will get their way and others will not. In these circumstances, the fact that a given option has some level of support is prima facie reason to suppose that it has some democratic credentials. The problem is that we need some fair way to decide which people will get their way when there is disagreement between them. A lottery over votes treats each person fairly, by giving each of them an equal chance of being decisive. It also, as shown later, encourages deliberation and attempts at persuasion.

Thus, it is far from clear whether intrinsic fairness favors majority rule. First, it seems that fairness may be at least equally satisfied by tossing a coin, instead of using any democratic procedure at all. Second, if we are to use a democratic procedure (perhaps because it is

40. This has not always been sufficiently appreciated by some democratic theorists, though others do emphasize the importance of agency, e.g., Fabienne Peter, Democratic Legitimacy (London: Routledge, 2009), 25-30.

41. I assume an egalitarian form of democracy, but saying that each vote should have equal influence is compatible with some people having more votes than others.

42. Taurek, "Numbers," 304-8. See also Kamm, "Equal Treatment," 178-80; Rob Lawlor, "Taurek, Numbers and Probabilities," Ethical Theory and Moral Practice 9 (2006): 14966, 150-59; and Weyma Lübbe, "Taurek's No Worse Claim," Philosophy and Public Affairs 36 (2008): 69-85.

43. Goodin, "Democracy, Justice and Impartiality," 99. 
likely to lead to better outcomes), then it is not obvious that fairness requires-or even is satisfied by-majority rule. This may be fair in some cases, like where all have an equal chance of being in the majority. Where there is a permanently excluded minority, however, majority rule seems unfair. In these cases, lottery voting, because it gives the minority a proportional chance of victory, seems both fairer and more democratic.

\section{INSTRUMENTAL ARGUMENTS FOR DEMOCRACY AND MAJORITY RULE}

It seems that the most obvious reasons to prefer democratic procedures to lotteries involve appeal to their consequences, whether making better decisions or having some positive by-products or side effects. The question is whether these considerations give us reason to adopt majority rule in particular. Some arguments for majority rule rest on its achieving better outcomes; for example, it might be maintained that the majority are more likely to identify substantively just outcomes for Condorcetian reasons or that the logic of the median voter theorem tends to encourage middle ground compromises that give everyone partial satisfaction. I shall address these particular arguments in the following section. For now, my concern is with the very general idea that democracy will promote better consequences.

Even without a specific account of why democracy should tend to produce good decisions, it may seem intuitively likely that deliberate choice by a group of people is likely to satisfy the weak condition of being better than random. This very general intuition does not, however, tell against lottery voting. Whichever vote is randomly selected will identify an option that someone has deliberately chosen, presumably because it seems good to them (not necessarily for them). Lottery voting therefore differs from a simple lottery in that it retains an element of deliberate, reasoned choice, so it should not be identified with decisions made at random. To suppose that majority rule is likely to produce better outcomes than lottery voting requires further argument.

There are at least three possible arguments that lottery voting may actually produce better outcomes than majority rule, at least in certain cases. First, as we saw above, where there is a fixed majorityminority division, majority rule is likely to lead to the same people getting their way all of the time. While minorities may have their basic rights protected by constitutional provisions, this is not enough. Intuitive standards of outcome fairness require each group to get some satisfaction, but permanent minorities may never be satisfied. While lottery voting does not guarantee proportionality of outcomes, it makes it likely that, over enough decisions, each group will get its way 
at least some of the time. Proportionality of outcomes is unlikely under majority rule because, even if all members of the majority agree that the minority should sometimes get their way and are willing to vote with the minority for this reason, there is no method of coordinating such "defection" to ensure that the minority are sometimes in a majority. ${ }^{44}$ Thus, one might think lottery voting likely to produce fairer outcomes in cases where there is a permanent minority who would otherwise be excluded by majority rule. Second, if we assume that there may be a wise minority in society, on at least some issues, then allowing them to get their way and be proved right means that in future more people may defer to their judgment, making it more likely that future decisions will be right. Third, as I will argue in the following section, lottery voting may do more to encourage deliberation, since one will always have an incentive to persuade as many voters as possible of the merits of one's case, and one may think that this will promote better outcomes.

None of these arguments are intended to be conclusive; my aim is merely to show that there are somewhat plausible arguments that lottery voting may produce better outcomes than majority rule, and thus one who favors an instrumental justification of democracy must still engage in further substantive argument as to whether that should be majoritarian. One might, nonetheless, still suspect that options preferred by a majority are likely to be better than those backed only by a few who happen to be lucky enough to have their votes selected. I shall come, later, to specific reasons why this may be so, such as an appeal to Condorcet's jury theorem or worry that extremist minorities may get their way. We might conjecture that majority rule will be preferable to lottery voting, because it reflects considerations seen as relevant by many, rather than being potentially hostage to a few unreflective voters. But, conversely, we might say that majorities may be subject to crowd psychology or that majority rule, by making outcomes appear certain, discourages reflection on alternatives. All of these arguments require further elaboration, but the point is that whether one seeking good outcomes prefers majority rule or lottery voting is a contingent matter, and both are possible democratic procedures that may be favored in different contexts.

I want at this stage simply to note one further weakness of outcome-based justifications of majority rule. It seems that many of them simply assume not only that there are right and wrong, or better and worse, answers to political problems but also that there is only one right answer. Consequently, there is a temptation to assume that one

44. The impossibility of coordinating this defection is therefore a problem for that solution, proposed by Rehfeld, The Concept of Constituency, 233-34. 
group-probably the majority-is more likely to have identified this answer and that others are wrong. This approach, however, overlooks the fact that indeterminacy may be prevalent in political decision making. As a number of theorists have observed, even if there are some wrong answers, politics often involves making decisions between two alternatives neither of which is objectively worse. ${ }^{45}$ One need not be a radical value pluralist to think that there will be cases of incommensurability, particularly (though not necessarily only) when we must trade one person's interests off against another's. Suppose, for example, that all agree on some general social goal, such as maximizing aggregate utility or the position of the worst off. This allows us to exclude many possible outcomes as suboptimal but is unlikely to determine exactly what we should do. Two or more alternatives may equally satisfy this aim, yet differ in terms of how well off particular individuals or groups are ${ }^{46}$ For example, if the total utility that we can achieve is five units, we may face the choice between distributing it $(3,2)$ or $(2,3)$ between two equal groups in society. Here is a conflict of interest, where each group can legitimately prefer that they be the better-off ones (within the constraints of justice) and we need a fair procedure to adjudicate between them.

This suggests that, while intrinsic fairness is not alone enough to justify democracy, neither is a concern for the best decisions. If neither outcome is impersonally better, we may still need a fair procedure to adjudicate between them and, since majority rule may be unfair to a permanent minority, lottery voting could be the most acceptable procedure ${ }^{47}$ Indeterminacy may also strike even where there is no conflict of interests; for instance, deliberations about capital punishment may have to weigh the values of justice, mercy, deterrence, and the risks of innocent deaths. It may be that there is no uniquely reasonable solution to this balancing act but, rather, a range of reasonable decisions (e.g., the death penalty may reasonably be retained for homicide, but not for shoplifting).

Instrumental defenses of democracy can also appeal to by-products of the process, rather than claiming it leads to better decisions,

45. For examples of such an observation, see David Miller, "Deliberative Democracy and Social Choice," in Debating Deliberative Democracy, ed. James Fishkin and Peter Laslett (Oxford: Blackwell, 2003), 184; and Philip Pettit, "Democracy, Electoral and Contestatory," in NOMOS XLII: Designing Democratic Institutions, ed. Ian Shapiro and Stephen Macedo (New York: New York University Press, 2000), 118.

46. A similar problem is that there may be disagreement over how to realize a shared end. See Robert Goodin and Geoffrey Brennan, "Bargaining over Beliefs," Ethics 111 (2001): 256-77, 258-61.

47. I argue for this at more length in "Why Majority Rule Cannot Be Based Only on Procedural Equality," Ratio Juris 23 (2010): 113-22. 
but it seems that any by-product identified as a possible justification of democratic procedures could also be the result of lottery voting. Mill, for example, emphasizes the fact that participating in collective decision making broadens people's horizons and encourages them to see the larger social good. ${ }^{48}$ Again, this is not obviously satisfied only by majority rule. Indeed, since the likelihood of any individual vote being pivotal to a winning coalition is so low, it seems that majority rule may encourage irresponsible voting. Mill suggests that each person should consider their vote as if they were the only voter and the decision depended entirely on them. ${ }^{49}$ Lottery voting encourages this attitude, because it may be that the outcome is decided solely by one's vote. Therefore, lottery voting may be more conducive to the educational benefits Mill identifies than majority rule.

Some of the arguments for majority rule offered in the next section are specific arguments that it will bring about better consequences. I shall argue there that none of these are generally successful. For the time being, however, the conclusion is that a commitment to democracy on instrumental grounds does not necessarily imply a commitment to majority rule. It is only a contingent defense of democratic procedures to begin with, and it will be a further empirical contingency whether majority rule or lottery voting is more likely to produce the good outcomes identified.

\section{ARGUMENTS FOR MAJORITY RULE}

So far, I have shown that no general argument for democracy, whether based on its intrinsic fairness, conduciveness to better decisions, or valuable by-products, necessarily implies majority rule. We can be democrats without being committed to majority rule and vice versa. Therefore, majority rule is something that must be argued for. Some have indeed recognized this fact and offered a variety of arguments for majority rule. This section surveys six such arguments, as identified by Risse in a skeptical survey. ${ }^{50}$ These are the perversity of minority rule, maximization of self-determination, respect, Condorcet's jury theorem, May's theorem, and compromise as a way of maximizing overall satisfaction. ${ }^{51}$ Risse claims that none of these arguments pro-

48. Mill, "Considerations," chap. 3.

49. Ibid., chap. 10, 355.

50. Risse, "Arguing," 44-45.

51. A further reason, suggested by an anonymous editor, is that people simply accept majority rule as obviously legitimate and thus decisions reached this way are likely to be stable. While it is true that majority rule is widely accepted, by many people in many contexts, it is not universally so. Moreover, there is no reason to suppose that this belief is somehow innate, as opposed to a product of our majoritarian institutions. If there is no more fundamental reason to think majority rule preferable to lottery voting, then the 
vide decisive support for majority rule, so we should look instead for "fair division" methods of decision making. I offer lottery voting as one such method, seeking to confirm his conclusions by testing lottery voting against the arguments he identifies for majority rule. My contention is that none of these provide a decisive general reason to favor majority rule over lottery voting.

\section{Minority versus Majority}

One argument for majority rule is simply that it would be perverse to hold a vote in which the smallest minority would get their way. The problem is not simply that we satisfy fewer people rather than more, but that such a system induces citizens to misrepresent their preferences, by voting for their least preferred option. ${ }^{52}$ This perversity, however, is the consequence of assuming a deterministic rule that the (smallest) minority will automatically win. This would not be the case with lottery voting. Though the minority could prevail, each vote still advantages whichever option it is cast for-increasing its chances of victory. It is therefore rational for people to vote for the option that they most favor. There is, therefore, nothing perverse about lottery voting. ${ }^{53}$

\section{Maximization}

It is often assumed that majority rule maximizes the number of people exercising self-determination. This is not necessarily so, though, if we take a long-term view. If we suppose, plausibly, that only those that get their way on a given decision are exercising self-determination, then it is true that majority rule maximizes the number exercising

belief is baseless. It may still be an obstacle to any attempt to implement lottery voting in practice but would not show that lottery voting could not equally be seen as legitimate and stable in a society where it was the established decision-making procedure.

52. Such a proposal is discussed by Jack Lively, Democracy (Oxford: Blackwell, 1975), 16 and 24 . He claims that people would simply vote for whichever option they liked least. In a binary case, assuming all voters acted in this way, this would simply result in majority rule. Where there are three or more options, however, it could deliver different outcomes, as it would result in the option least acceptable to the fewest people. For example, if four people rank (A, B, C), two rank (A, C, B), and five rank (B, C, A), then A wins a majority of first preferences $(6: 5: 0)$. If the option with the fewest votes wins, and individuals vote for the option that they least prefer, then the distribution of votes will be (5:2:4), so B will win with only two votes. See also Kamm, "Equal Treatment," 182 n. 4.

53. This shows that those who simply contrast the permanent rule of a majority or a minority are drawing a false dichotomy. Abraham Lincoln does this in his "First Inaugural Address," which is quoted by Risse, "Arguing," 61; and Dahl and Lindblom, Politics, Economics and Welfare, 44. Lottery voting means that neither the majority nor the minority get their way all the time. 
self-determination on that given issue. ${ }^{54}$ If we have five people vote one way and three vote the other, then the best that we can do is have five self-determining. But this consequence does not necessarily hold over a series of decisions. If we regularly face the same division of opinion, then always satisfying the five means that the three people never get their way, and so are denied any self-determination (at least, in collective decisions).

Majority rule may maximize the amount of self-determination, if it is reasonable to think of this in consequentialist terms. Five people self-determining in each of eight decisions results in 40 "units" of selfdetermination. This self-determination is not, however, distributed fairly-the five get their way on all eight decisions and the three not at all, which could be represented as $(8,8,8,8,8,0,0,0)$. If we were to let each group decide on a proportional number of decisions, then we would get less aggregate self-determination-just 34 units, that is $(5,5,5,5,5,3,3,3)$-but not only would this be more fairly distributed, there would be more people exercising some self-determination, since all eight people now have some share. Lottery voting does not guarantee proportionality, but we can assume that over a long series of decisions all could get their way sometimes; thus everyone is able to exercise some self-determination, which seems preferable to some enjoying full self-determination at the expense of a persistent minority's total exclusion.

\section{Respect}

Majority rule is supposed to satisfy the need for a decision while allowing each person to remain faithful to his conviction. Epistemic justifications, which claim the majority more likely to be right, may have difficulty explaining persistent minority opposition. ${ }^{55}$ One may, however, endorse majority rule because it respects each person's judgment, without claiming rightness. Vernon, for example, argues that the majority verdict need not produce better outcomes or even better reflect the preceding deliberation. Rather, his case rests simply on two facts: "Majority rule has the virtue of encouraging the generalization of political argument, which is an important service to public

54. I assume that self-determination here means something like autonomy (living according to one's own choices), and thus only those who get their way are truly selfdetermining. An anonymous editor for the journal questions whether self-determination requires winning a vote, as opposed to merely participating in it. If self-determination means merely participating in decision making, then it provides a better defense for democracy (since we can say that all are self-determining), but no defense at all for majority rule in particular. It is also the case that all participate in lottery voting.

55. See Robert Goodin, "The Paradox of Persisting Opposition," Philosophy, Politics and Economics 1 (2003): 109-46. 
reason; and it also has the virtue that because the counting of votes records a fact, it can yield the unequivocal answer that we need in order to have a political authority. Both of these justifications have weight even for the outvoted. . . But the idea that democratic majorities are in some way authoritative, even temporarily, with respect to the issues that public reason debates, is one that minorities have no reason to accept." ${ }^{56}$

Lottery voting, however, seems to better satisfy these desiderata. Certainly it provides a determinate outcome to settle disputes, providing clear guidance when the need for action comes. It also seems to give more reason to generalize one's appeal, since every vote helps one's cause. Under majority rule, the side with a healthy majority has no incentive to appeal to the minority, provided that they are confident of not losing their own supporters. Lottery voting would mean that no group could ever be guaranteed success, short of achieving unanimous support, so it is always rational to seek more support. This would also apply to minorities with no hope of ever winning a majority-they would increase their chances of success if they could increase their level of support, even from 10 percent to 20 percent.

\section{Condorcet's Jury Theorem}

Condorcet's jury theorem, which is essentially an application of the law of large numbers, shows that if there are right answers to political questions and voters are more likely than not to identify these, then a majority of voters are more likely to get things right than any single individual. If the conditions of the jury theorem hold, then it provides good reason to go along with the verdict of the majority, since they are most likely to have identified the right answer. However, it is not obvious that these conditions do hold in most cases of political decision making. While the theorem can be generalized to cases where not all voters are more likely right than wrong, provided that competence is evenly distributed and the mean remains over $0.5,{ }^{57}$ and to cases with more than two options, provided that voters are more likely to choose the right one than any wrong one ${ }^{58}$ it is still questionable whether even these weaker conditions are satisfied.

More fundamentally, one does not have to reject any talk of truth in politics to think that there is room for indeterminacy. While we might all be able to agree that some outcomes are better than others,

56. Vernon, Political Morality, 142.

57. Bernard Grofman, Guillermo Owen, and Scott Feld, "Thirteen Theorems in Search of the Truth," Theory and Decision 15 (1983): 261-78.

58. Christian List and Robert Goodin, "Epistemic Democracy: Generalizing the Condorcet Jury Theorem,” Journal of Political Philosophy 9 (2001): 277-306. 
there may also be conflicts where it makes no sense to suppose that either outcome is "generally better"- that is, where we effectively have a straightforward conflict of interests. In these cases, we need a rule that aims at a fair division. Lottery voting will only produce outcomes that someone has voted for; so, provided that all are reasonably competent and well motivated, this will prevent disastrous outcomes (I say more about this below). At the same time, lottery voting ensures that competing groups have a fair opportunity to get their way when matters come down to conflicts of interest or opinion.

\section{May's Theorem}

May showed that simple majority rule is the only determinate decision rule that satisfies four seemingly attractive conditions when choosing between two options. ${ }^{59}$ The conditions are decisiveness: for any inputs, there must be some choice, even if it is indifference; anonymity: all voters are equal, so two switching their votes would not change the outcome; neutrality: no option is favored, so had all voters switched their votes the outcome would be reversed; and positive responsiveness: if the group decision is either favorable to $\mathrm{X}$ or a tie, and any one individual switches in a way favorable to $\mathrm{X}$ while no one else changes, then the decision becomes strictly favorable to $\mathrm{X}$. If we find each of these four conditions compelling, then we should favor simple majority rule, because no other alternative satisfies them all.

May's theorem cannot, strictly, be construed as an argument for majority rule, though it may function as a lemma within such an argument. ${ }^{60}$ May's theorem itself is merely a formal definition, and it would be a normative argument only if each condition was either obviously attractive or argued for independently. The fact that we sometimes employ decision rules other than simple majority rule indicates that, sometimes at least, we find one or more of these conditions unnecessary. May himself notes, for example, that we may prefer to violate neutrality and entrench certain constitutional rights. ${ }^{61}$

Further, there are two crucial assumptions made by May's theorem, which limit its usefulness in an argument for majority rule. First, it is constrained to binary choices. Since political decisions are rarely simple yes/no questions, but often permit of a range of options including compromises (e.g., on budget spending), it is not obvious that May's theorem is relevant. There are, of course, a number of

59. Kenneth O. May, "A Set of Independent Necessary and Sufficient Conditions for Simple Majority Decision," Econometrica 20 (1953): 680-84.

60. See Ackerman, Social Justice, 277-85; and Beitz, Political Equality, 58-67.

61. May, "Necessary and Sufficient Conditions for Simple Majority Decision," 681 n. 7. 
ways in which a larger number of options can be reduced to two before a vote, for example through first-round votes or agenda rules, but, since these can effectively determine the outcome, the meaningfulness of the majority choice at the end stage can be questioned ${ }^{62}$ Second, May's argument is restricted, without explicit justification, to determinate social decision rules, which excludes a procedure like lottery voting a priori.

Since the formal definitions of May's conditions assume a deterministic procedure, they are not satisfied by lottery voting. Nonetheless, if these conditions are found intuitively appealing, then it is most likely in some more general way, since our intuitions do not well track technical definitions. Lottery voting satisfies intuitive criteria of anonymity and neutrality, since it does not favor any voter or option, is decisive since an option is always picked, and is positively responsive in a weaker sense, since extra votes in favor of one option always increase its chances of winning. It seems that this captures the main intuitive appeal of May's conditions.

\section{Compromise}

Finally, it may be suggested that majority rule maximizes overall satisfaction, not because more people get their way rather than fewer, but because it represents an averaging of individual rankings. This can be understood as an application of Downs's median voter theorem. ${ }^{63}$ Where two parties compete on a single dimension, the median voter will be pivotal to forming a winning majority, so majority rule favors "middle ground" solutions. While those on either extreme may never get their way, they will be less dissatisfied with such an outcome than if the opposing side had got things all their way.

This argument makes certain assumptions about the shape of people's preferences; specifically that they are single peaked, so individuals always prefer outcomes closer to their ideal point to ones further away. It is perfectly reasonable in some cases for people's preferences to be multipeaked though. For instance, if we were considering spending on some project, one may think that either no spending or a high amount is preferable to assigning a low budget that will not get the job done properly. Under these circumstances, a middle ground position may simply dissatisfy everyone. ${ }^{64}$ It may be that, as

62. William H. Riker, Liberalism against Populism: A Confrontation between the Theory of Democracy and the Theory of Social Choice (San Francisco: W. H. Freeman, 1982), 60.

63. See Duncan Black, "On the Rationale of Group Decision-Making," Journal of Political Economy 56 (1948): 23-34; and Anthony Downs, An Economic Theory of Democracy (New York: Harper \& Row, 1957).

64. For similar cases, where simply "splitting the difference" is no good as a compromise, see Goodin and Brennan, "Bargaining over Beliefs," 264-66. 
with dividing indivisible goods, each side would prefer some chance of getting all of what they want, to a compromise that is little-if any-better than none of what they want. It should be remembered that lottery voting was justified as this sort of compromise-proportionate chances rather than proportionate results. The result may well be more unequal, because it is effectively winner takes all, but each side may ex ante prefer it to any other compromise (or, at least, to any compromise that could be produced in such a mechanistic fashion).

\section{OBJECTIONS TO LOTTERY VOTING}

It seems that none of the common arguments for majority rule provide a decisive general justification for preferring it to lottery voting. However, it may be replied that this is because they have rarely had such a target in mind and that there are other objections that rule out lottery voting. ${ }^{65}$ These objections are strictly beside the point, insofar as lottery voting is simply a heuristic to illustrate shortcomings in arguments for majority rule. We have seen that some common arguments for majority rule, such as appeals to Condorcet, are simply not compelling, while others, such as respect-particularly in the form employed by Vernon-actually seem to favor lottery voting. This is my first, and main, contention: that we need to pay more attention to potential alternatives to majority rule.

A qualified defense of lottery voting in particular is only my secondary purpose. I do not need to show that it is the best democratic procedure, only that it has some plausibility in certain circumstances, to show that majority rule stands in need of (better) justification. Circumstances conducive to lottery voting include cases where there is a conflict of interests between rival groups, where no option is objectively terrible, rather than purely "factual" disputes ${ }^{66}$ No doubt it is also more likely to be justified in cases where there are high degrees of trust between decision makers and relatively small stakes, for example, when a group of friends are choosing a restaurant for dinner, but perhaps this is because these conditions are most favorable to democracy.

More seriously, lottery voting is only motivated where a persistent minority would otherwise be excluded altogether from decision making. If the majority and minority form fluidly on each issue, then we

65. Jon Elster, Solomonic Judgements: Studies in the Limitations of Rationality (Cambridge: Cambridge University Press, 1989), 86-91.

66. The line between 'facts' and 'values' is blurred. I think there are right and wrong answers to questions about justice, morality, etc., but by 'factual' here I mean 'nonevaluative' questions, such as "how tall is Everest?" or "did X shoot Y?" 
can assume that all individuals will have a greater chance of ending up in the majority than not, so allowing the majority to rule would be both fair and likely to maximize aggregate satisfaction. In such circumstances, lottery voting would still be democratic and egalitarianthat is, a way of reaching a group decision that respects each person's preferences equally-but it would not likely be the best democratic procedure. Where majority rule does not suffer serious defects, it may well be preferable, since holding a lottery would often mean fewer people being satisfied. The contexts in which lottery voting may be suitable are those where some persistent minority know in advance that majority rule will see them lose. In those cases, I think they can reasonably reject majority rule as rigged, rather than fair.

No doubt a number of objections to lottery voting will already have occurred to the reader. I shall consider what I take to be the four most common and serious objections to lottery voting, namely, that it (i) can allow extreme or undesirable minorities to win; (ii) fails to live up to its promise of equality, because outcomes may still be unequal; (iii) neglects the importance of deliberation; and (iv) may result in inconsistent sets of decisions. Note, however, that I cannot provide a full treatment of the many ways in which lottery voting could be institutionalized, which obviously are as variable as the implementation of majority rule. In either case, we face a variety of decisions about, for example, judicial review or agenda control. My point is simply that the obvious problems with lottery voting can be overcome.

\section{Extreme Minorities}

I have suggested that persistent minorities should have a chance of getting their way. It may be replied that this is not so-that their being a persistent minority is a reason for them not getting their way, since their position is obviously unattractive to others and their arguments unpersuasive ${ }^{67}$ One might, for example, focus on extremist minorities, such as those who join the Ku Klux Klan or British National Party. Of course, not all minorities are racists or neofascists, but if we give all minorities a chance then even these groups may sometimes win, which might be disastrous. While majority rule may exclude many

67. Rehfeld, The Concept of Constituency, 232, argues that the permanence of a minority suggests that they should not get their way, citing the example of the Ku Klux Klan. The reason the KKK's policies should not be enacted, however, is because they are unjust, not because they are a minority-we would not want them enacted even if the KKK won a majority. Not all minorities advocate objectionable policies, however. Moreover, the persistence of a minority may be due to the difficulty that some, such as cultural groups, have in making their case persuasive to mainstream society. See Vernon, Political Morality, 14867. 
reasonable small groups at least it also has the virtue of excluding extremist fanatics and permitting only what a large number find reasonable. Thus, while it may not deliver ideal outcomes, we may think that it has the virtue of avoiding the worst ones. ${ }^{68}$

The defender of lottery voting might reply that it would be democratic to give even these minorities a chance of having their policies enacted, if people vote for them. Democracy is not, after all, all good things but simply a system of popular rule and, if the people vote for injustices, then it is unsurprising that democratic outcomes may prove to be unjust. This could be reason to resist democracy tout court, but it is not an objection to the democratic status of lottery voting. After all, one need not think that all decisions are appropriately made democratically-some, for instance, those where important rights are at stake, might be better made either by "experts" or small deliberative bodies. Where these groups are likely to result in substantively better decisions being made then we may prefer such nondemocratic procedures. Nonetheless, the advocate of lottery voting is not committed to accepting the victory of extremist minorities.

First, it may be replied that what is wrong with such groups winning is not that they are minorities but that their policies are unjust. If we subscribe to the idea of liberal rights as "trumps," then we would not think that these policies ought to be implemented even if they won a majority. The usual solution is to give courts the power to strike down legislation that violates rights, even when it is in accordance with the preferences of the majority, and the same option is open to the advocate of lottery voting. Judicial review (where it works as intended) effectively takes unjust options off the political menu, which reduces the risks of giving all remaining alternatives a chance. Thus, democratic values may be traded off against the value of substantively just outcomes. Once the possibility of rights violations is removed, it is less clear that there is anything wrong in these groups having their preferences satisfied.

Second, it should be noted that although the logic of proportionality requires that all groups get the chance that they are entitled to, we might in practice choose to limit this proportionality by imposing some minimum threshold of votes before a group (or the option they support) receives any chance. This is in keeping with the practice of many countries practicing "proportional representation," where minimum thresholds (usually around 5-10 percent) are often required before a party gets any representation. A similar restriction can be applied in the cases of decision making that I am concerned with. We might insist that a given option needs the support of at least

68. Estlund, Democratic Authority, 160-67. 
10 percent of voters to be given any chance of victory, to rule out options favored only by a few crackpots, but give all options that satisfy this threshold a chance of victory proportionate to their level of support among voters. This excludes options favored by only a very small minority of the voters, which may again compromise the democratic or egalitarian nature of the system, but does so in order to prevent the risk of substantively bad outcomes.

Third, we might suggest a bit more faith in the people. It is true that we do sometimes observe people voting for undesirable extremists, but it should not be forgotten that voting behavior is to a considerable extent endogenous to the political system. Majoritarian systems, in both elections and referenda, allow for large numbers of protest votes, because one can be reasonably sure that an extremist party or option is unlikely to win. There is considerable evidence, both scientific and anecdotal, that much of the extremist voting we observe in such systems is simply protest voting. ${ }^{69}$ It is hard to predict the consequences on voting behavior of switching to a more proportional voting rule, such as lottery voting. Certainly it is likely to favor many existing minority options, once votes cast for them are seen as having a real chance of winning, rather than being "wasted." On the other hand, it may be that extremist parties actually receive less support as people cast their votes more responsibly once they really mean something. ${ }^{70}$

This objection can, however, be developed by pointing out that lottery voting creates incentives for extremism rather than compromise. ${ }^{71}$ Majority rule forces parties to make wider appeals and to seek mutually agreeable compromises. While lottery voting rewards those that are able to persuade more people to their cause, it does not likewise encourage moderation-there is no reason to accept half the cake, if one has a chance of getting all of the cake. This means that there may be a tendency for groups to make unreasonable demands,

69. For examples of protest voting, see Nonna Mayer and Pascal Perrineau, "Why Do They Vote for Le Pen?" European Journal of Political Research 22 (1992): 123-41. A Palestinian voter is quoted as saying that he only voted Hamas to shock the Fatah Party and would not have done so had he expected that they might win, in Harry de Quetteville, "The Regretful Fatah Voters Who Took Poll 'Game’ Too Far,” Daily Telegraph (January 27, 2006), 5. Orit Kedar, "When Moderate Voters Prefer Extreme Parties: Policy Balancing in Parliamentary Elections," American Political Science Review 99 (2005): 185-99, notes that voters exaggerate the intensity of their preferences to balance out the centralizing effect of voting systems. That the inconsequentiality of an individual vote frees voters to vote on noninstrumental (e.g., ethical) grounds is argued by Geoffrey Brennan and Loren Lomasky, Democracy and Decision: The Pure Theory of Electoral Preference (Cambridge: Cambridge University Press, 1993).

70. Mill, "Considerations," chap. 10, 353-55.

71. I owe this objection to Clare Chambers. 
knowing that they may have the luck to get all that they want. I have already pointed out that groups may sometimes be reasonable in preferring a chance of getting all their way to a compromise that does not satisfy anyone. Nonetheless, it would be a serious problem if lottery voting encouraged and rewarded groups advancing unreasonable claims.

Perhaps the fact that anyone could lose will encourage all to think more seriously about the position of losers. Moreover, we might make institutions less susceptible to abuse, for example, by requiring public voting, so that those who press unreasonable claims will have to do so openly and can be held to account informally. ${ }^{72}$ If we adopt public voting, then it seems that there is more prospect for groups to reach a compromise through discussion or logrolling, because they can be assured that others will offer their promised support. Ultimately, since no institution is immune to abuse, we may have to trust to the reasonableness of the people. Well-functioning democracy requires high levels of interpersonal trust and self-restraint. Most people do seem to consider the general good or justice, rather than merely their own private interests, when voting. Since lottery voting encourages personal responsibility among voters, we may hope that most will refrain from advancing extreme positions, while those we deem unjust may be checked by judicial review.

\section{Unequal Outcomes}

A second objection is that lottery voting will not actually result in equality. There are two ways that this can be taken, but both rest on misconceptions about the purpose of lottery voting. First, it has already been pointed out that the aim is not equal satisfaction or equal chances for everyone. It will still be the case that members of a minority are less likely to get their way, but this is a consequence of treating each person equally: more do count for more, in that they have a greater chance of winning, but (unlike majority rule) the numbers are not fully determinative, so the minority also get their chance. The minority need not be resigned to their position, since a further virtue of the system is that they can improve their odds by winning more voters over to their cause, thereby improving their chances of victory. I shall say more about deliberation shortly, but there is a second interpretation of the unequal outcome objection.

It may be accepted that treating people equally requires proportionality, rather than giving the majority all their own way, but still

72. Public voting was also advocated by Mill, "Considerations," chap. 10. See Annabelle Lever, "Mill and the Secret Ballot: Beyond Coercion and Corruption," Utilitas 19 (2007): 354-78. 
objected that lottery voting does not guarantee proportional outcomes. This is not simply a repeated call for results proportionate to numbers, rather than chances proportionate to numbers; for the objector may also accept the impossibility of reaching a satisfactory compromise on each and every individual decision. It may be accepted that we need to look for compromise over a series of decisions, but objected that lottery voting does not ensure that each group will get its way a specified proportion of the time-it may be, for example, that an unlucky minority group still loses every time. If we wanted to ensure that all groups sometimes got their way, then a better procedure might involve some determinate form of rotation or turn taking that ensures all groups are actually satisfied on some occasions, rather than merely having a chance of satisfaction on all occasions that may never in fact come up.

I think any such proposal would be impractical, however, for it is unclear how it would work if the groups were not fixed and it would doubtless increase efforts to manipulate the agenda, as each group tried to ensure that it was "their turn" when an important decision came up. The rationale for lottery voting is not to ensure that each group gets its preferred outcome a specified portion of the time, though this would probably be a welcome consequence if it happened. Groups give up their claim to proportionate outcomes in favor of proportionate chances and, in doing so, accept that-because chance is inherently uncertain-they may win or lose more than their "fair share." Fairness, however, is respected in the procedure itself, rather than outcomes. Even if a minority have, as it happens, lost every time up until now, where lottery voting differs from majority rule is that they can go in to the next vote with a real chance of winning, rather than knowing in advance that they will lose.

\section{Deliberation}

The third serious objection to lottery voting is that it neglects, or even undermines, the important role of deliberation and reason giving in democracy. In fact, this is no more true than to say that majority rule necessarily does so. It is true that groups may refuse to enter into deliberation and simply trust to their chance, just as majority groups can refuse to listen to minorities and have their way by force of numbers in majoritarian systems. As already observed though, institutions can be designed to allow, and even encourage, deliberation before matters come to the vote. Since even the most hardened deliberative democrat usually recognizes the practical impossibility of reaching complete consensus through deliberation, lottery voting simply replaces majority rule as a last resort once discussion is over, either because there is no more to be said or no more time to say it. Indeed, 
lottery voting may do more to encourage attempts at persuasion, because all groups have incentives to try to persuade as many others as they can to their cause, since this will increase their chances of winning, whether or not they have any hope of persuading a majority.

It may be objected that this is not sufficiently responsive to the outcomes of reason giving. Suppose, for example, that opinion was initially evenly divided between two options but, after deliberation, a majority had formed, so the balance of opinions stood at 75/25. This is a fairly dramatic shift and arguably indicates that the balance of reasons favors the former alternative. ${ }^{73}$ It is true that lottery voting does not ensure that the former option will win the election, even though it could be said to have won the argument. There are, however, a number of points to be made here.

One might question the assumption that the argument for the former option is obviously stronger. It is true that opinion has swayed that way, but it was not a decisive victory because it did not win everyone over. Had deliberation resulted in unanimity, then lottery voting would trivially respect this (since whichever vote was chosen would be for the unanimously preferred option). As it is, however, 25 percent remain unpersuaded-so, if the reasons were not convincing to them, it is not obvious that they should be taken as decisive. We must remember that the majority may not necessarily have converged upon a uniquely correct outcome. The reason for persistent disagreement may be that there is a conflict of interests, where the minority are legitimate in preferring some other option.

Moreover, the "responsiveness to reasons" argument does not generally favor majority rule. This is evident if we imagine another example, where opinion was initially split $90 / 10$ but, after deliberation, this became $60 / 40$. Here we might think that the stronger arguments actually favor the minority, for they had clearly been more persuasive in the debate; but majority rule would not reflect this and would still have the former side win. Neither lottery voting nor majority rule guarantees that the side with the better arguments will get its way, but lottery voting at least ensures that the more people you persuade the greater your chances of victory. This seems sufficiently responsive to the results of deliberation.

\section{Inconsistency}

Even if lottery voting is no worse than majority rule in deciding particular issues, one may worry that the overall package of decisions that results will be worse, since different factions may get their way each time and hence the result may be an inconsistent patchwork with no 
coherent rationale. ${ }^{74}$ In other words, the set of decisions will lack what Dworkin calls integrity. ${ }^{75}$ It should be noted, however, that majority rule does not guarantee consistency either. Suppose we must decide whether to (i) lower taxes, (ii) increase education spending, and (iii) increase defense spending. Assume that we can do any two (we could lower taxes and increase defense spending by cutting the education budget), but not all three. Nonetheless, it may be that different majorities form in favor of all three options. ${ }^{76}$ The problem here seems to be precisely that there is no fixed majority but, rather, a series of fluid coalitions-exactly the situation that many regard as most hospitable to majority rule. Perhaps the lesson is that we face an inevitable trade-off between the fairness of ensuring that all get some satisfaction and the consistency provided by having one group (or one individual) decide everything.

It would indeed be a problem if any decision procedure was to yield flatly contradictory decisions, such that we should both raise and lower taxes. We need not, however, resign ourselves to such inconsistencies. Much depends on how the overall range of decisions is broken down into discrete "units" for the vote. It may be that there are some cases where to do $\mathrm{X}$ would be pointless unless we also do $\mathrm{Y}$, and vice versa. In these cases, it seems sensible to have one vote on whether or not to do both $\mathrm{X}$ and $\mathrm{Y}$ together, rather than separate votes on each. There may, however, be other cases where policy $\mathrm{Z}$ seems a "natural complement" to X, but it may be worthwhile doing either thing separately. In these cases, we could take the votes separately, but it would be sensible to make the outcome of the first public before votes were cast on the second. That way, those who wanted to do $\mathrm{Z}$ if and only if $\mathrm{X}$ would know whether $\mathrm{X}$ and be able to vote accordingly. If it happened that $\mathrm{Z}$ was chosen, despite not-X, it would only be because there were some people who thought $\mathrm{Z}$ the best thing to do, even though it has been decided that $\mathrm{X}$ will not be done.

Before lottery voting could be implemented, much more thought would need to be given to agenda-setting mechanisms. We may, for example, need ways to stop defeated groups bringing the same policy immediately back to the table, hoping to get lucky next time. One

74. I thank an anonymous referee for prompting me to discuss these concerns here.

75. Ronald Dworkin, Law's Empire (Cambridge, MA: Harvard University Press, 1986), 176-224. It should be noted, however, that integrity matters only for matters of 'principle', not 'policy'. Moreover, judges are tasked with interpreting the law as if it had a single author/rationale, though it does not, which is consistent with lottery voting as well as changeable majorities.

76. This structure parallels that described in Christian List, "The Discursive Dilemma and Public Reason," Ethics 116 (2006): 362-402, but concerns distinct, though interdependent, decisions. 
solution might be for all policies to enjoy protected status for a period of time that could be set for each decision by a separate but simultaneous vote. This would force all involved to converge on a reasonable protection period, since they would have to nominate a time balancing the risk of being stuck under a policy that they dislike and the protection they would want if they were to win the substantive vote.

I cannot explore all possible institutional permutations, which are as varied for lottery voting as for majority rule. There is no need, however, to fear that lottery voting will necessarily result in contradictory policies and, if there is a loss of coherence, it is simply a natural result of distributing decision-making power fairly to all groups. Inconsistency is not always an issue, though, since some cases may necessarily be one-off decisions. Moreover, we must remember that similar problems also plague majority rule, particularly in cases of "cyclical" majorities.

\section{CONCLUSION}

The choice of the appropriate decision-making rule seems to depend upon the context and what is to be decided. There can be no general choice between majority rule and lottery voting, but the latter may be preferable in certain circumstances, for example, where it gives a permanent minority hope of having their preferences satisfied sometimes. Exactly when it would be preferable is a matter for further investigation, but, if it is a possible democratic procedure that cannot be ruled out a priori, it shows that more care needs to be taken to justify majority rule in particular, rather than only the more general principles of democracy or political equality. 